\title{
Progresso temporal da ferrugem em diferentes genótipos de pessegueiro
}

\author{
Leandro Luiz Marcuzzo ${ }^{1}$, Juliano Evandro dos Santos $^{1}$
}

${ }^{1}$ Instituto Federal Catarinense - IFC/Campus Rio do Sul, CP 441, CEP 89.163-356, Rio do Sul, SC

Autor para correspondência: Leandro Luiz Marcuzzo (leandro.marcuzzo@ifc.edu.br)

Data de chegada: 05/09/2016. Aceito para publicação em: 01/03/2017.

$10.1590 / 0100-5405 / 168153$

\section{RESUMO}

Marcuzzo, L.L.; Santos, J. E. Progresso temporal da ferrugem em diferentes genótipos de pessegueiro. Summa Phytopathologica, v.43, n.2, p.151-154, 2017.

A ferrugem do pessegueiro causada por Tranzschelia discolor é uma das doenças que comprometem a área foliar da cultura durante todo o período vegetativo, causando prejuízos à produção e a qualidade dos frutos. Considerando que o progresso temporal desta doença é pouco conhecido, esse trabalho teve como objetivo avaliar o progresso da doença ao longo do ciclo produtivo entre diferentes genótipos. O experimento foi realizado em pomar de pessegueiro do Instituto Federal Catarinense (IFC) Campus Rio do Sul. Foram avaliados os genótipos Granada, Dourado 1, Dourado 2, Douradão, Ouro, Chimarrita, Flordaprince, Premier, Aurora e Della Nona. Selecionaram-se quatro plantas de cada genótipo e avaliou-se a severidade da doença semanalmente, após o inicio da brotação, em 16 folhas de cada planta com auxilio de uma escala diagramática. A curva de progresso da doença para cada um dos genótipos foi ajustada a um modelo logístico, já que a severidade observada correspondeu ao modelo e foi confirmada pela coerência entre os pontos estimados e pelo resíduo. Foi verificado que o genótipo Dourado1 apresentou a maior taxa da doença $(0,645)$, enquanto Aurora, a menor $(0,330)$. Verificou-se que o genótipo Douradão apresentou o pico máximo da doença com $2,4 \%$ de severidade e que Chimarita e Dourado 1 tiveram o menor acúmulo da doença com $0,5 \%$. Os genótipos apresentaram diferentes comportamentos de progresso da ferrugem do pessegueiro.

Palavras-chave: Prunus persica, epidemiologia, Tranzschelia discolor.

\section{ABSTRACT}

Marcuzzo, L.L.; Santos, J. E. Temporal progress of rust in different genotypes of peach. Summa Phytopathologica, v.43, n.2, p.151-154, 2017.

Peach rust caused by Tranzschelia discolor is one of the diseases that affect the crop leaf area throughout the growing season, causing damage to production and fruit quality. Considering that the temporal progress of this disease is little known, this study aimed to evaluate the disease progress throughout the productive cycle among different genotypes. The experiment was carried out in a peach orchard at "Instituto Federal Catarinense-IFC"/Rio do Sul Campus. Evaluated genotypes were Granada, Dourado 1, Dourado 2, Douradão, Ouro, Chimarrita, Flordaprince, Premier, Aurora and Della Nona. Four plants from each genotype were selected and the disease

Keywords: Prunus persica, epidemiology, Tranzschelia discolor severity was weekly evaluated, using a diagrammatic scale, after the start of sprouting in sixteen leaves from each plant. The disease progress curve for each genotype was adjusted to a logistic model, since the observed severity corresponded to the model and was confirmed by the consistency between the estimated points and by the residue. Dourado 1 genotype showed the highest disease rate $(0.645)$ while Aurora showed the lowest rate $(0.330)$. Douradão genotype showed the highest disease peak with $2.4 \%$ severity, and Chimarita and Dourado 1 had the lowest disease accumulation, $0.5 \%$. Genotypes showed different peach rust progress behavior.
O pessegueiro (Prunus persica (L.) Batsch) é uma das espécies frutíferas adaptadas tanto para as condições de clima tropical quanto subtropical e seu cultivo vem crescendo em todo o mundo, devido à sua utilidade para industrialização e comercialização, na forma de sucos e enlatados (11). Porém, nesta cultura são diversos os fatores que contribuem para a sua baixa produtividade, e entre esses estão às doenças de etiologias diversas, as quais causam prejuízos significativos à cultura. A ferrugem, causada por Tranzschelia discolor (Fuckel) Tranzschel e Litvinov, figura entre as doenças fúngicas foliares que comprometem a produtividade da cultura (7).

O uso de genótipos resistentes é uma das formas de manejo dessas doenças, porém é necessária a avaliação do progresso da doença entre diferentes genótipos. No estudo de epidemias, a dinâmica temporal das doenças de plantas tem sido enfatizada, pois o progresso de doenças é freqüentemente a manifestação mais facilmente visualizada (6). Na análise temporal de doenças, a curva de progresso é a melhor representação de uma epidemia e a interpretação do formato dessas curvas e seus componentes, como intensidade inicial de doença, taxa de progresso e intensidade final são fundamentais para o manejo racional de epidemias ao conhecer em detalhe o a reação dos genótipo à ferrugem (5).

Mediante o exposto, o objetivo deste trabalho foi avaliar o progresso da ferrugem em diferentes genótipos de pessegueiro.

O trabalho foi realizado em pomar de coleção de genótipos de pessegueiro, localizado no Instituto Federal Catarinense (IFC), Campus de Rio do Sul, no município de Rio do Sul, SC, com latitude $27^{\circ} 11$ ' $22^{\prime}$ ' S, longitude, 49 $39^{\circ} 48^{\prime \prime} \mathrm{W}$ e altitude de 655 metros acima do nível do mar.

A avaliação foi realizada no período de 01/09/2010 a 24/03/2011, durante 30 semanas. Os genótipos avaliados foram Aurora, Chimarrita, Della Nona, Douradão, Dourado 1, Dourado 2, Flordaprince, Granada, Ouro e Premier. Todos os genótipos estavam com 12 anos 

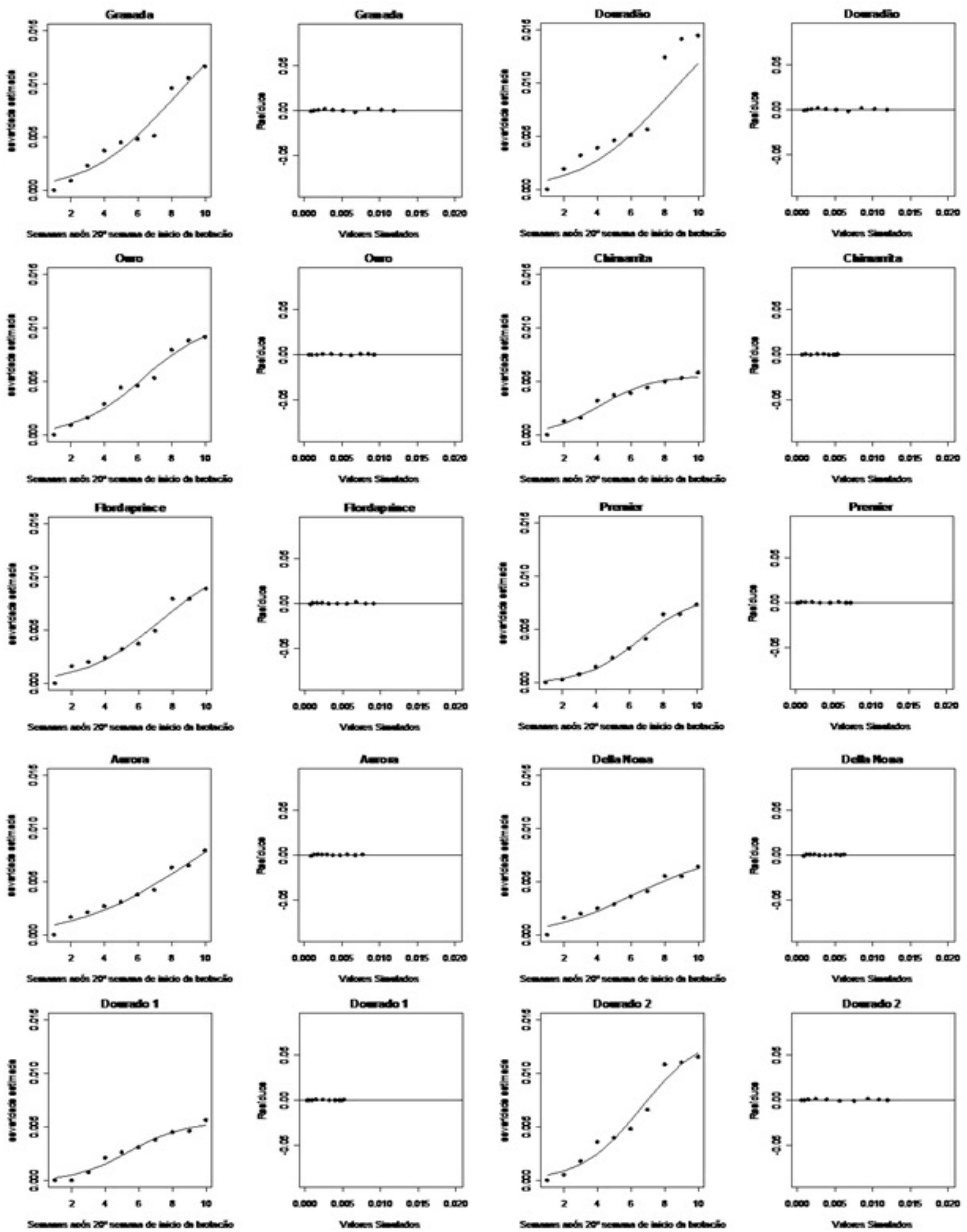

Figura 1. Severidade estimada do progresso da ferrugem em diferentes genótipos de pessegueiro e seus respectivos resíduos ajustados pelo modelo logístico a partir da $20^{\mathrm{a}}$ semana após o inicio da doença. 
de idade, enxertados em Capdeboscq, conduzidos em forma de taça. O espaçamento no pomar era de 6,5 metros entre linhas e 5 metros entre plantas. O delineamento experimental utilizado foi o de blocos casualizados, constituídos por uma planta por repetição e quatro repetições em cada genótipo.

O solo no local do experimento era do tipo cambissolo distrófico, relevo suavemente ondulado, $\mathrm{com} \mathrm{pH}$ em água $=6,1$, Fósforo $=3,0 \mathrm{mg}$ / $\mathrm{dm}^{3}$, Potássio $=72,0 \mathrm{mg} / \mathrm{dm}^{3}$, Matéria orgânica $=3,4 \%$ e Argila $=21 \%$.

Os tratos culturais foram realizados conforme o sistema de produção da cultura e o controle de insetos foi realizado através de armadilha contendo suco de uva (9). A temperatura média durante a condução do experimento foi de $18^{\circ} \mathrm{C}$ com acumulado de $768 \mathrm{~mm}$ de precipitação.

A avaliação da severidade da ferrugem foi realizada semanalmente após o início da brotação em 16 folhas por planta previamente marcada, totalizando 64 folhas avaliadas por genótipo. A porcentagem de severidade da ferrugem foi determinada segundo uma escala diagramática proposta por Rodrigues et al. (12) com valores de 0,8; 2,$4 ; 4,5$ e $13,7 \%$ de severidade.

Modelos não lineares, comumente usados para representar crescimento de epidemias como o Logístico e o de Gompertz foram usados para ajuste com os dados observados utilizando o software $\mathrm{R}$ versão 2.15.1(10). Os critérios estabelecidos para comparação dos modelos, em função da qualidade do ajustamento dos dados foram: a) erro padrão da estimativa; b) estabilidade dos parâmetros; c) erro padrão dos resíduos; d) visualização da distribuição dos resíduos ao longo do tempo e e) pseudo $\mathrm{R}^{2}$.

O modelo logístico representado por: $\mathrm{y}=\mathrm{ymax} /(1+\exp (-\ln (\mathrm{yo} /$ (ymax-yo)-r*x)), onde y é a intensidade final de doença; ymax, intensidade máxima da doença; $\ln$ (yo/(ymax-yo) refere-se a função de proporção da doença na primeira observação; $r$ corresponde à taxa; e $\mathrm{x}$, ao tempo em semanas, foi o que melhor se ajustou para representar o progresso da ferrugem do pessegueiro. Esse modelo foi o que apresentou o melhor ajuste quanto à curva de progresso da doença (Figura 1) policíclica.

A avaliação dos dados e as equações originadas pelo modelo logístico (Tabela 1) resultaram em um coeficiente de determinação significativo e a severidade observada corresponde ao modelo, confirmada pela coerência entre os pontos estimados e do resíduo (erro) nas 30 semanas de avaliação (Figura 1).

A severidade de ferrugem foi diferenciada entre os genótipos (Figura 1). Sintomas iniciais da doença foram observados a partir da décima quinta semana no genótipo Douradão, e apenas na vigésima terceira semana no Premier. O progresso da doença foi acentuado no Douradão, enquanto os demais genótipos tiveram comportamento semelhante entre a vigésima primeira e vigésima sétima semana (Figura 1). Alves (2) avaliando o genótipo Chimarrita quanto ao progresso da ferrugem constatou que a doença já iniciou a partir da primeira semana, mas isso pode ser atribuído ao inóculo que permaneceu nos ramos durante o inverno.

A taxa de progresso da doença foi diferente entre os genótipos (Tabela 1). No genótipo Dourado1 foi observada a maior taxa $(\mathrm{r}=0,645)$ devido à menor, $0,5 \%$, durante o período avaliado, mas similar ao Chimarrita que teve taxa de 0,642 . O Douradão foi o que teve maior acúmulo da doença com 2,4\% (Tabela 1). O genótipo Dourado 2 também apresentou severidade de 1,3\%, o que também foi verificado por Barbosa et al. (4) nesse genótipo.

No entanto, o crescimento da severidade é dependente da presença do patógeno no ciclo anterior da planta e o início da infecção é relacionado à quantidade de inóculo inicial disponível na área (5)
Tabela 1. Coeficiente de determinação $\left(\mathrm{R}^{2}\right)$ e os parâmetros estimados pelo modelo logístico ajustado aos dados de progresso da ferrugem do pessegueiro em diferentes genótipos

\begin{tabular}{lcccc}
\hline Genótipo & $\mathbf{y m a x}$ & $\mathbf{y o}$ & $\mathbf{r}$ & $\mathbf{R}^{2}$ \\
\hline Granada & 0,017 & 3,288 & 0,407 & 0,953 \\
Douradão & 0,024 & 3,570 & 0,413 & 0,933 \\
Ouro & 0,010 & 3,201 & 0,503 & 0,973 \\
Chimarrita & 0,005 & 2,659 & 0,642 & 0,961 \\
Flordaprince & 0,012 & 3,184 & 0,430 & 0,964 \\
Premier & 0,008 & 4,180 & 0,632 & 0,987 \\
Aurora & 0,012 & 2,769 & 0,330 & 0,961 \\
Della nona & 0,007 & 2,449 & 0,397 & 0,961 \\
Dourado 1 & 0,005 & 3,488 & 0,645 & 0,968 \\
Dourado 2 & 0,013 & 3,770 & 0,567 & 0,967 \\
\hline
\end{tabular}

$\mathrm{y}=\mathrm{ymax} /(1+\exp (-\ln (\mathrm{yo} /(\mathrm{ymax}-\mathrm{yo})-\mathrm{r} * \mathrm{x}))$, onde y é a intensidade final de doença;

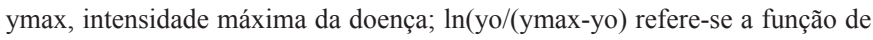
proporção da doença na primeira observação; $r$ corresponde à taxa $\mathrm{e} x$, ao tempo em semanas.

Martins (8). trabalhando com o genótipo de pessegueiro Flor da Prince, também verificou aumento progressivo da doença à medida que aumentava a idade das folhas. Rodrigues et al. (12) constataram $1,41 \%$ de severidade final, índice abaixo do encontrado nesse trabalho (Tabela 1). Alves (1) encontrou correlação positiva entre a desfolha em pessegueiro e a severidade de ferrugem, no entanto, nesse trabalho, não ocorreu desfolha, decorrente da baixa severidade da doença entre os genótipos. Assmann et al. (3) também não observaram imunidade à ferrugem em avaliação de genótipos e descrevem que a eficiência de infecção é diferenciada, indicando a presença do tipo de resistência horizontal.

Conclui-se que os genótipos avaliados apresentaram diferentes comportamentos de progresso da ferrugem. O genótipo Chimarrita e Dourado 1 apresentaram a menor intensidade da doença, enquanto que Douradão, a maior intensidade da ferrugem, entre os genótipos de pessegueiro.

\section{REFERÊNCIAS}

1. Alves, G.; May-de-Mio, L.L.; Zanette, F.; Oliveira, M.C. Ferrugem do pessegueiro e seu efeito na desfolha e na concentração de carboidratos em ramos e gemas. Tropical Plant Pathology, Brasília, v.33, n.5, p.370-376, 2008.

2. Alves, G. Avaliação de danos causados pela ferrugem em pomar de pessegueiro da cultivar Chimarrita. Curitiba, 2006. 84p. Dissertação (Mestrado em Produção Vegetal) - Universidade Federal do Paraná.

3. Assmann, A.P. Citadin, I.; Santos, I.; Wagner Júnior, A. Reação de genótipos de pessegueiro à ferrugem-da-folha. Pesquisa Agropecuária Brasileira, Brasília, v.45, n.1, p.32-40, 2010.

4. Barbosa, W.; Campo-Dall'orto, F.A.; Ojima, M.; Kalil, G.P.C.; Lovate, A.A.; Ribeiro, I.J.A. Incidência de ferrugem em folhas de pessegueiro e nectarineira do germoplasma IAC. Scientia agrícola, Piracicaba, v.51, n.1, p. 90-93, 1994.

5. Bergamim Filho, A.; Amorim, L. Doenças de plantas tropicais: epidemiologia e controle econômico. São Paulo: Ceres, 1996, 289p.

6. Campbell, C.L.; Madden, L.V. Introduction to plant disease epidemiology. New York: Wiley Interscience, 1990. 532p.

7. Martins, M.C.; Betti, J.A; Leite, R.M.V.B.C.; Leite, R.P.; AMORIM, L. Doenças de rosáceas de caroço. In: Kimati, H.; Amorim, L.; Rezende, J.A.M.; Bergamim Filho, A.; CAMARGO, L.E.A. Manual de Fitopatologia: doenças de plantas cultivadas. São Paulo: Ceres, v.2, 3 ed. Cap.62. 
p.545-557, 2005.

8. Martins, M.C. Quantificação dos parâmetros monolíticos e controle químico da ferrugem do pessegueiro. Piracicaba, 1994. 68p. Dissertação (Mestrado em Fitopatologia) - Universidade de São Paulo.

9. Medeiros, C A.B.; Raseira, M.C.B. A cultura do pessegueiro. Brasília: EMBRAPA-SPI, 1998. 350p.

10. R Development Core Team (2012). R: A language and environment for statistical computing. R Foundation for Statistical Computing, Vienna,
Austria. Disponível em: $<$ http://www.R-project.org $>$. Acesso em: 15 fev. 2016.

11. Raseira, M.C.B.; Quezada, A.C. Pêssego produção. Embrapa Clima Temperado. Brasília: EMBRAPA, 2003 (Informações Tecnológicas, frutas do Brasil n.49). 162p.

12. Rodrigues, A.; Scarpar Filho, J.A.; Araújo, J.P.C.; Girardi, E.A.; Scarpare, F.V. Intensidade de poda verde em pessegueiro para controle da ferrugem Tranzschelia discolor (Fuckel) Tranzschel e Litvinov. Revista Brasileira de Fruticultura, Jaboticabal, v.30, n.3, p.634-638, 2008. 